\title{
URGENSI PENANAMAN AQIDAH DALAM PENDIDIKAN ISLAM
}

\author{
Fitriana* \\ Fitrifirda99@gmail.com \\ *Dosen Magister Pendidikan Agama Islam, Universitas Muhammadiyah Tangerang
}

\begin{abstract}
Aqeedah is not just a belief that is in the hearts of men. But aqeedah is essentially a strong belief that is able to encourage a Muslim to want to do or do good deeds. If someone's true and lurius aqidah, then it will be true and straight also the path taken, and vice versa. Aqeedah is a major problem in the teachings of Islam. Because it involves the fundamental beliefs of all deeds. Muslims and non-Muslims can be distinguished from the side of amaliyah or his actions; whether reflecting Muslim's amaliyah or not. What is done is worth the good in the eyes of humans. Departing from this, the writer tries to actualize the urgency of planting aqidah in Islamic education. and behavior patterns based on pure Islamic aqeedah.
\end{abstract}

Keywords: Urgency, Aqidah Cultivation, Islamic Education

\section{A. PENDAHULUAN}

Aqidah merupakan pondasi utama yang ditegakkan oleh ajaran agama islam. Bahkan ma'rifatullah dan keimanan kepada Allah merupakan asas dakwah para rosul ketika di utus di muka bumi. Dan syareat Islam menghendaki umatnya agar memiliki aqidah yang lurus yang tercermin dalam prilaku keseharian yang benar sesuai perintah Allah SWT dan RosulNya.

Pendidikan islam memiliki peran dan andil yang besar dalam hal ini, karena tujuan asasi pendidikan islam diantaranya adalah menjadikan anak didik menyakini ajaran agamanya dengan sepenuh hati, menghayati dan mengaplikasikan asas keyakinan yang kuat terpatri tersebut dalam keseharian di kehidupan nyata. Hal ini bukanlah hal yang tabu dalam dunia pendidikan islam, karena sejak awal dalam generasi awal kaum muslimin, sudah dicontohkan oleh Rosulullah SAW dan para sahabatnya. Mereka mengatakan bahwa kami mempelajari ilmu dan keimanan secara bersamaan.

Sehingga menjadi jelas bahwa pemasalahan aqidah atau ketauhidan bukanlah persoalan teori semata namun lebih kepada penanaman kesan mendalam di dalam jiwa, yang kemudian dapat memberikan pengaruh dan berdaya guna bagi arah tujuan hidup manusia yang hakiki, yaitu menggapai ridho Allah SWT. Jika tidak demikian, maka aqidah hanya akan dianggap sebatas sisi pengetahuan saja tanpa keimanan yang hidup didalam hati, dan akibatnya menjadi semakin jauhlah sebuah realita daripada sebuah kewajiban dan pengamalan dari ilmu.

Beranjak dari hal tersebut, maka yang sangat dibutuhkan adalah kembali mengkontekstualkan penanaman dasar aqidah dalam pendidikan islam. Untuk mempelajari keimanan dan membangun sebuah aqidah yang terpaut kuat dalam keyakinan akal dan keimanan hati, sehingga nampaklah pengaruhnya dalam prilaku dan perbuatan secara istiqomah sesuai perintah Allah SWT. 


\section{B. PEMBAHASAN}

\section{Dasar dan Prinsip Pendidikan Aqidah}

Adapun yang menjadi dasar serta landasan utama dalam pendidikan aqidah adalah Al-Qur'an dan as-Sunnah. Artinya apa saja yang disampaikan Allah SWT dalam Al-Qur'an dan oleh rasul-Nya dalam sunnahnya maka wajib diimani dan diamalkan. ${ }^{1}$

Selama berpegang pada keduanya, maka kehidupan yang dijalani tidak akan tersesat dan salah arah, rosul SAW bersabda:

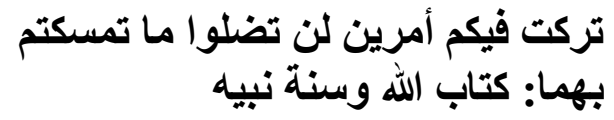

Aku tinggalkan untuk kalian dua perkara, tidak akan sesat kalian selama berpegang teguh pada keduanya: alqur'an dan sunah nabinya. ${ }^{2}$

\section{a. Al-Qur'an al Karim}

Ditinjau dari sumber hukum, maka posisi Al-Qur'an merupakan sumber yang utama. Sebagai landasan hukum, hal tersebut mengandung makna bahwa kedudukan Al-Qur'an itu sendiri adalah sumber dari segala sumber ajaran islam. Bahkan ianya menjadi penegas,di bidang aqidah, serta memberi motivasi bagi manusia untuk dapat mengembangkan ilmu pengetahuan dan teknologi yang dimiliki.

Adapun secara spesifik, fungsi asasi Al-Qur'an diantaranya:

\section{Berfungsi sebagai petunjuk}

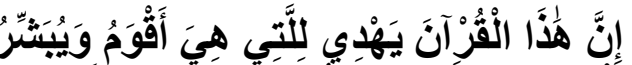

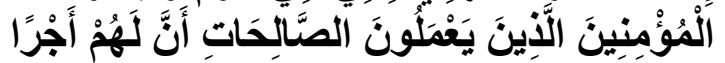

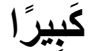

1 Yunahar Ilyas, Kuliah Aqidah Islam, (Yogyakarta: Lembaga Pengkajian dan Pengamalan Islam (LPPI) Universitas Muhammadiyah Yogyakarta, 1993), h.6

2 Malik bin Anas bin Malik, al Muwatho', muassasah zain bin sulthan - abu dhabi-imarat, 2004, juz 5, bab annahy an qaul bin qadr, hal 1323.
"Sesungguhnya Al Quran Ini memberikan petunjuk kepada (jalan) yang lebih lurus dan memberi khabar gembira kepada orangorang Mu'min yang mengerjakan amal saleh bahwa bagi mereka ada pahala yang besar,

" ( Q.S 17:9)

\section{Berfungsi sebagai penjelas}

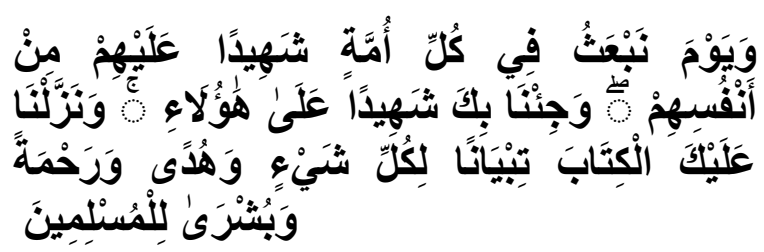

"(Dan ingatlah) akan hari (ketika) kami bangkitkan pada tiap-tiap umat seorang saksi atas mereka dari mereka sendiri dan kami datangkan kamu (Muhammad) menjadi saksi atas seluruh umat manusia. dan kami turunkan kepadamu Al Kitab (Al Quran) untuk menjelaskan segala sesuatu dan petunjuk serta rahmat dan kabar gembira bagi orang-orang yang berserah diri." (Q.S 16:89)

\section{Berfungsi sebagai pembeda.}

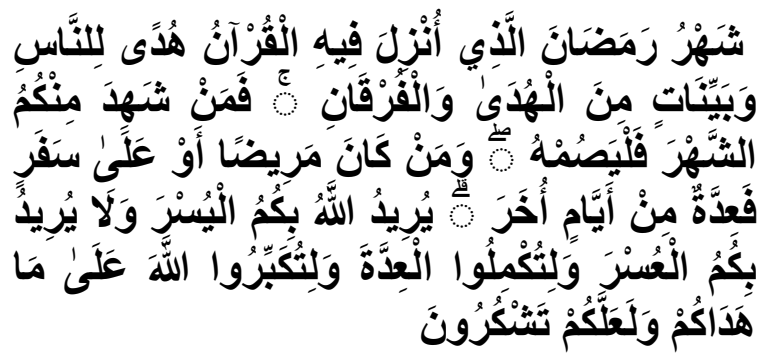

"Beberapa hari yang ditentukan itu ialah) bulan Ramadhan, bulan yang di dalamnya diturunkan (permulaan) Al Quran sebagai petunjuk bagi manusia dan penjelasanpenjelasan mengenai petunjuk itu dan pembeda (antara yang hak dan yang bathil). Karena itu, barangsiapa di antara kamu hadir (di negeri tempat tinggalnya) di bulan itu, Maka hendaklah ia berpuasa pada bulan itu, dan barangsiapa sakit atau dalam perjalanan (lalu ia berbuka), Maka (wajiblah baginya berpuasa), sebanyak hari yang ditinggalkannya itu, pada hari-hari yang lain. Allah menghendaki kemudahan bagimu, dan tidak menghendaki kesukaran 
bagimu. dan hendaklah kamu mencukupkan bilangannya dan hendaklah kamu mengagungkan Allah atas petunjuk-Nya yang diberikan kepadamu, supaya kamu bersyukur." (surah AlBaqarah :185)

\section{b. As-Sunnah/al Hadis}

Sunnah atau alhadis adalah sumber hukum islam kedua setelah Al-Qur'an. Mencakup segala perkataan, perbuatan, dan taqrir (yaitu baik dengan diam atau persetujuan) yang bersumber dari nabi SAW. Sehingga timbullah istilah sunnah qauliyyah, sunnah fi'liyyah, dan sunnah taqririyah.

Adapun fungsi assunnah sebagai sumber hukum kedua setelah AlQur'an,terinci sbb:

1. Berfungsi sebagai penegas dan penguat hukum-hukum yang telah ditentukan oleh Al-Qur'an.

contohnya:seperti hadis yang berisi penjelasan waktu berpuasa dan berbuka.

\section{صومو الروئيه وافطروا لرؤيته}

Berpuasalah kalian ketika melihatnya(hilal), dan berbukalah ketika melihatnya. ${ }^{3}$

2. Berfungsi sebagai penjelas ayat-ayat alQur'an.

contohnya:seperti penjelasan tata cara sholat sebagaimana sabda nabi SAW:

Sholatlah kalian sebagaimana kalian

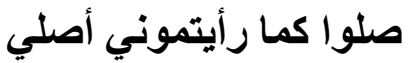
melihatku sholat. $^{4}$

3.berfungsi sebagai penetap hokum yang tidak terdapat penjelasannya di dalam alQur'an.

contohnya: seperti keharaman memakan khimar (keledai) peliharaan. ${ }^{5}$

\footnotetext{
${ }^{3} \mathrm{Al}$ imam anNawawy, Riyadhusholihin, Dar al afaq arabiyah,Kairo, bab annahyi an taqaddm ramadhan ba'da nisf sya'ban illa liman washolahu bima qablahu.auwafaqa adat lahu.,juz 2, hal 69

${ }^{4}$ Muhammad bib Hibban bin Ahmad bin Muaz bin ma'bad atTamimy abu Hatim adDarimy, Shohih Ibnu Hibban, muassasah al risalah, Beirut 1993, bab al-azan juz 4, hal 503.
}

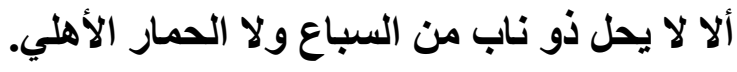

"Tidak halal (memakan) binatang buas bertaring, dan khimar (keledai ) peliharaan

Dengan demikian, maka Al-Quran sebagai sumber segala sumber hukum Islam hanyalah memuat prinsip-prinsip dasar ajaran Islam. Adapun sebagian ayatnya yang menguraikan prinsip-prinsip dasar tersebut secara rinci yang merupakan contoh dan petunjuk bahwa seluruh kandungan Al-Qur'an masih perlu penjelasan. Penjelasan al-Qu'an dapat dijumpai dalam sunnah Rasul. Sunnah rasul itu merupakan cerminan dari segala tingkah laku Rasulullah saw yang harus diteladani. Inilah salah satu alat pendidikan yang paling efektif dalam pembentukan pribadi. Karena keglobalan Al-Qur'an dan tidak dapat diurai kecuali melalui sunnah rasul, maka sumber kedua setelah Al-Qur'an ialah sunnah rasul tersebut. ${ }^{7}$

Dan termasuk prinsip pokok dalam pendidikan islam adalah mengacu kepada Al-Qur'an dan sunnah. Hal ini bermakna bahwa pendidik dan peserta didik harus dapat memahami dengan baik kandungan Al-Qur'an dan sunnah, tentunya dengan menambah istimbath dan ijtihad ulama yang tidak bertentangan dengan Al-Qur'an dan sunnah.

\section{Ruang Lingkup Pendidikan Aqidah}

Ruang lingkup pendidikan aqidah merupakan rincian daripada rukun iman yang enam, yaitu: ${ }^{8}$

1). Ma'rifat kepada Allah

Ma'rifat Kepada Allah adalah seluhur-luhur dan semulia ma'rifat,

5 Dr.M,Ajaj alKhathib, Usul al-Hadis,Gaya Media Pratama,semarang 1997, hal 39.

${ }^{6}$ Abu Daud Sulaiman bin Asy'as Sajastany, Sunan Abu Daud, dar al kitab al araby, Beirut, bab nahyi an akli assiba', juz 3, hal 418.

7 Abidin Ibn Rusn, Pemkiran al-Ghozali Tentang Pendidikan, (Yogyakarta: Pustaka Pelajar, 1998) h. 131.

${ }^{8}$ Sayyid Sabiq,Al Aqaid al Islamiyah, dar al kitab al 'araby, beirut, muqaddimah . 
sebab Ma'rifat Kepada Allah itulah yang merupakan asas atau fundamental yang diatasnya didirikanlah segala kehidupan kerohanian.caranya dengan menggunakan akal pikiran untuk memikirkan dan memperhatikan segala sesuatu yang diciptakan oleh Allah.serta mengenal nama-nama Allah dan sifat-sifat-Nya.

Iman kepada Allah mencermikan hubungan paling mulai antara manusia dengan Penciptanya. Hal ini dikarenakan makhluk yang paling mulia di muka bumi adalah manusia, dan sesuatu yang ada di dalam diri manusia yang paling mulia adalah hatinya, sedangkan sesuatu yang ada di dalam hati yang paling mulia adalah keimanan

2). Ma'rifat kepada malaikat atau alam yang ada dibalik alam semesta ini atau alam yang tidak dapat dilihat.

Tabiat Malaikt adalah secara sempurna berbakti kepada Alloh, tunduk dan patuh pada kekuasaan dan keagunganNya, melaksanakan seua perintahnya dan mereka ikut mengatur hal-ihwal alam emsta ini, dengan mengikuti kehendak dan iradah Alloh SWT. ${ }^{9}$

3). Ma'rifat kepada Kitab-kitab Allah yang diturunkan untuk menentukan rambu-rambu kebenaran dan kebathilan.

Adapun kitab-kitab yang tercatat dan dapat kita ketahui yaitu ada 4 kitab diantaranya kitab Taurat diturunkan untuk nabi Musa a.s.,kitab Injil kepada Nabi Isa a.s., kita zabur kepada nabi Daud a.s. dan Al-Qur'an kepada Nabi Muhammad SAW. Kitab-kitab tersebut berisi petunjuk dan cahaya penerang bagi manusia.

Kitab Al-Quran diturunkan kepada nabi terahir yaitu nabi muhammad SAW yang memiliki beberapa keistimewaan dari kitab-kitab yang lain yaitu Al-Qura'an kitab terahir yang menyempurnakan kitab-kitab sebelumnya dan ajaranya akan tetap berlaku sepanjang masa dan tetapt terjaga keasliannya oleh Alloh SWT.

4). Mar'rifat kepada para nabi dan rasul Allah yang telah dipilih untuk menjadi pembimbing dan pemimpin makhluk menuju kepada yang hak.

Allah SWT mewajibkan atas setiap oarng-orang beriman untuk percaya kepada rasul-rasukNya tanpa membedakan antara yang satu dengan yanglainnya. Apabila seseorang sudah beriman kepada sebagian rasul dan mengkari sebagian yang lain, maka ia jelas menjadi orang kafir.

Setiap ummat mempunyai rasul, tidak ada satu umat pun dalam suatu masa kecuali semuanya dikirimkan rasul oleh Alloh SWT, yang bertugas mengajak mereka untuk berbakti kepada Alloh SWT menuju jalan yang benar sekaligus menjadipemimpin mereka.

Rasul adalah seorang manusia lakilaki dari ummat itu sendiri yang dipilih oleh Allah untuk menerima wahyu dan untuk disampaiakan kepada ummatnya. Tugas utam rasul adalah untuk mengajak ummatnya untuk beribadah kepada alloh SWT dan menegakkan agamaNya.

5). Ma'rifat kepada hari akhir dan halhal yang ada didalamnya.

Keimanan pada Allah SWT dan hari akhir memiliki peran besar dalam keistiqomahan seorang hamba, dan orang yang mengetahui bahwa di sana ada penghisaban atas apa-apa yang dilakukan dari kesalahan-kesalahan, dan di sana juga ada penjara untuk orang-orang yang durhaka. Oleh karena itu, hal ini mendorongnya agar terhindar dari kemaksiatan, dan jika suatu saat tergelincir maka dengan segera

${ }^{9}$ Ibid, hal 17 dan 111.

Tadarus Tarbawy. Vol. 1 No. 2 Jul - Des 2019. ISSN. 2657-1285 e-ISSN. 2656-8756 
ia meminta ampun dan menyesali serta memohon pengampunan.

Dan amal perbuatan yang telah dilakukan manusia selama hidup di dunia akan menetukan kondisi saat dia dibangkitkan, ada yang dibangkitkan dalam kondisi yang sempurna, kurang sebagian, dan berbagai jenis kondisi lainnya sesuai dengan kadar amal perbuatannya di dunia.

6). Ma'rifat terhadap qadar (takdir).

Beriman kepada takdir yaitu memberikan pelajaran kepada manusia bahwa segala sesuatu yang ada dalam alam semesta ini hanya akan berjalan sesuai dengan kebijaksanaan yang telah digarisakan oleh Dzat yang maha tinggi. Oleh sebab itu, jika ia tertimpa musibah ia tidak akan menyesal, juga ketika tertimpa pertolongan dan keuntungan dia tidak bergembira sehingga lupa daratan. ${ }^{10}$

Secara ringkas menurut sayyid sabiq cakupannya adalah :

1) mengenai Allah, zatNya, sifatsifatnya, dan af'alnya

2) mengenai kenabian dan kerasulan

3) mengenai hal yang ghoib, dan

4) hari kiamat ${ }^{11}$

Mengenai empat hal tersebut diatas, sudah banyak diterangkan secara luas dan berulang didalam alqur'an dan hadis.sehingga tidak dibutuhkan tambahan penjelasan.Hanya perlu diperingatkan bahwa dalam mempelajari persoalan tauhid hendaknya orang membatasi diri pada apa yang terdapat dalam alqur'an dan hadis dan tidak perlu melantur membicarakan pada banyak hal yang menjadi bahan perdebatan. Karena yang menjadi tujuan dari pelajaran tauhid ialah agar tertanam iman yang

${ }^{10}$ Sayyid Sabiq Al Aqaid al Islamiyah, hal 159, 171, 257.

11 Sayyid Sabiq,Sumber Kekuatan Islam,penerbit pt bina ilmu,Surabaya,1980,hal 118. teguh dan aqidah yang mantap pada diri seorang, dan dengan demikian terbentuklah kekuatan positif pada jiwa yang mendorongnya melakukan hal-hal yang besar dan luhur. ${ }^{12}$

\section{Urgensi Penanaman Aqidah Dalam Pendidikan Islam}

Semua yang ada di alam semesta ini, memberi tanda adanya wujud Allah dan bahwa dunia ini mempunyai pencipta dan pemeliharanya. 13 Sebagaimana termaktub dalam surah alJatsyiah:3-5:

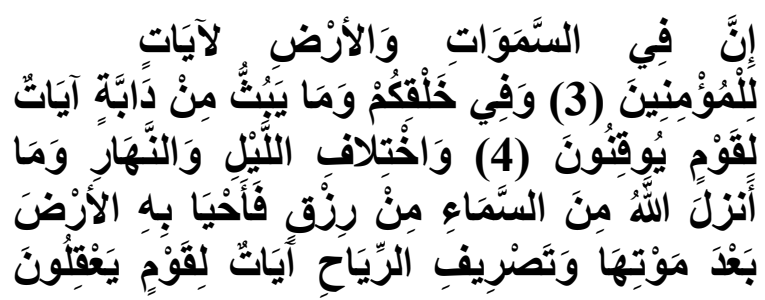
5))

3. Sesungguhnya pada langit dan bumi benar-benar terdapat tanda-tanda (kekuasaan Allah) untuk orang-orang yang beriman.

4. Dan pada penciptakan kamu dan pada binatang-binatang yang melata yang bertebaran (di muka bumi) terdapat tandatanda (kekuasaan Allah) untuk kaum yang meyakini,

5. Dan pada pergantian malam dan siang dan hujan yang diturunkan Allah dari langit lalu dihidupkan-Nya dengan air hujan itu bumi sesudah matinya; dan pada perkisaran angin terdapat tanda-tanda (kekuasaan Allah) bagi kaum yang berakal.

Kepercayaan akan adanyya tuhan yang menciptakan alam semesta ini adalah suatu fitrah yang telah tertanam dalam naluri manusia yang diciptakan oleh allah dengan fitrah itu.itulah yang oleh para ulama disebut " religious instinct" instink agama. $^{14}$

\footnotetext{
12 Ibid.

${ }^{13}$ Ibid, hal 13

${ }^{14}$ Ibid,hal 14.
} 


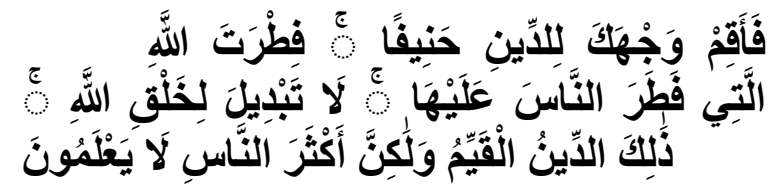

"Maka hadapkanlah wajahmu dengan lurus kepada agama Allah; (tetaplah atas) fitrah Allah yang Telah menciptakan manusia menurut fitrah itu. tidak ada peubahan pada fitrah Allah. (Itulah) agama yang lurus; tetapi kebanyakan manusia tidak mengetahui. ${ }^{15}$ Surah ar-Ruum:30

Wujud Tuhan Yang Maha Kuasa merupakan suatu hakikat yang tidak dapat diingkari. Dan jangkauannya hingga seluruh alam semesta, semua benda dan makhluk. Tuhan sangat dekat dengan manusia , Dia mendengar doa hambaNya, memperkenankan permohonan dan harapan hamba-hambaNya. Allah SWT berfirman dalam alQur'an surah AlBaqarah:186:

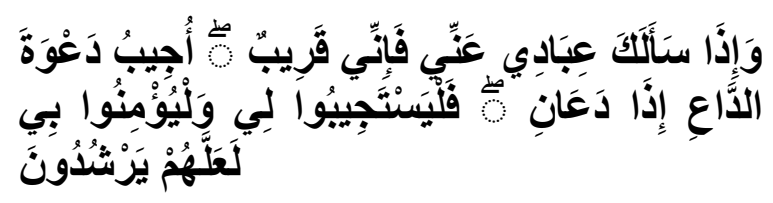

"Dan apabila hamba-hamba-Ku bertanya kepadamu tentang aku, Maka (jawablah), bahwasanya Aku adalah dekat. Aku mengabulkan permohonan orang yang berdoa apabila ia memohon kepada-Ku, Maka hendaklah mereka itu memenuhi (segala perintah-Ku) dan hendaklah mereka beriman kepada-Ku, agar mereka selalu berada dalam kebenaran."

Dari uraian diatas mengenai hakikat keimanan terhadap wujud tuhan, maka pendidikan islam merupakan satu-satunya cara untuk menanamkan aqidah yang murni disertai budi pekerti mulia. Karena agama dengan pengaruh aqidah keimanan yang

15 fitrah Allah: maksudnya ciptaan Allah. manusia diciptakan Allah mempunyai naluri beragama yaitu agama tauhid. kalau ada manusia tidak beragama tauhid, Maka hal itu tidaklah wajar. mereka tidak beragama tauhid itu hanyalah lantara pengaruh lingkungan. Qur'an in Word ver 1.0.0 (Mushaf alQur'an dan terjemahannya )created by Mohamad Taufik. kuat terhadap jiwa seseorang dapat membentuk mental luhur dan mampu membangkitkan naluri yang peka dalam dirinya, naluri yang mana akan menjadi pengontrol bagi tindak tanduknya, pendorong untuk beramal sholih dan menjadi pencegah dari perbuatan-perbuatan yang tidak patut. ${ }^{16}$

Kepekaan naluri dan kesadaran jiwa yang demikian itu merupakan intisari dan hakikat iman serta bibit aqidah yang mantap, Rasul SAW bersabda,ketika ditanya para sahabatnya tentang tanda-tanda iman :

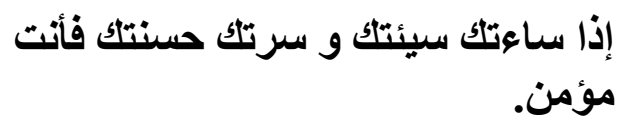

Jika engkau merasa resah karena berbuat dosa dan merasa puas dan senang karena berbuat kebaikan , maka engkau orang mukmin. ${ }^{17}$

Secara rinci urgensi penanaman aqidah dalam pendidikan islam,diantaranya,yaitu:

1) Aqidah merupakan misi utama ajaran islam yang dibawa oleh para Rasul utusan Allah SWT.

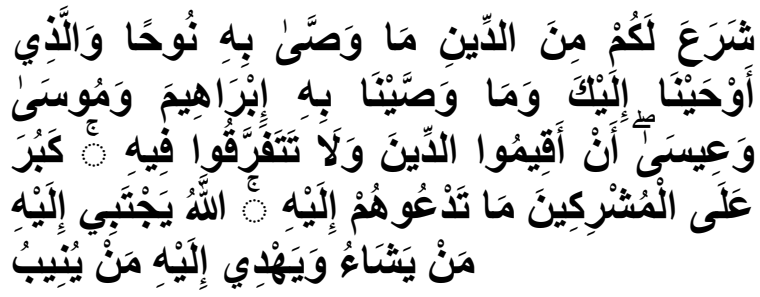

"Dia Telah mensyari'atkan bagi kamu tentang agama apa yang Telah diwasiatkanNya kepada Nuh dan apa yang Telah kami wahyukan kepadamu dan apa yang Telah kami wasiatkan kepada Ibrahim, Musa dan Isa yaitu: Tegakkanlah agama ${ }^{18}$ dan

\footnotetext{
${ }^{16}$ Sayyid Sabiq,sumber kekuatan islam,penerbit pt bina ilmu,Surabaya,1980, hal 68.

${ }^{17}$ Ahmad bin hanbal, Musnad al imam ahmad bin hanbal,Muassasah arRisalah, cet ke2, 1999, juz 36, hal 484.

${ }^{18}$ yang dimaksud: agama di sini ialah mengEsakan Allah s.w.t., beriman kepada-Nya, kitabkitab-Nya, rasul-rasul-Nya dan hari akhirat serta mentaati segala perintah dan larangan-Nya.
} 
janganlah kamu berpecah belah tentangnya. amat berat bagi orang-orang musyrik agama yang kamu seru mereka kepadanya. Allah menarik kepada agama itu orang yang dikehendaki-Nya dan memberi petunjuk kepada (agama)-Nya orang yang kembali (kepada-Nya).'(surah Asy-Asyura :13)

Aqidah harus ditanamkan sejak awal di kehidupan manusia sebagai bekal perjalanan menuju keselamatan hidup dalam naungan ridhoNya. Dan menjadi urgent dalam pendidikan islam untuk mewujudkan generasi yg beraqidah murni dan lurus sebagaimana hal ini juga ditanamkan oleh Rosul SAW kepada para sahabat dan umatnya. Sebab Aqidah merupakan satu kesatuan yang tidak berubah dikarenakan pergantian zaman dan tempat, dan tidak pula berganti sebab perbedaan golongan atau pun masyarakat.

2). Aqidah ibarat pondasi utama pada bangunan. Seberapa besar kuatnya pondasi utama, maka sebesar itu pula kekuatan bangunan yang akan ditegakkan. Dan jikalau pondasi utama tersebut kuat dan kokoh maka ianya akan mengokohkan bangunan yang lainnya seperti ibadah,muamalah dan akhlak.

3). Aqidah yang kokoh merupakan motivasi murni untuk berprilaku baik dan beramal sholih. Hal ini karena keimanan bukan sekedar angan -angan,tetapi pembuktian dalam amal perbuatan.

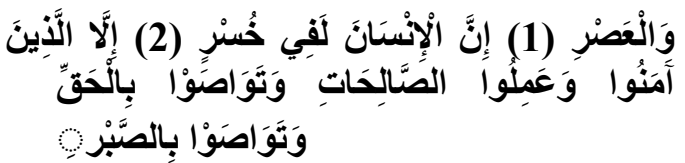

Demi masa.2. Sesungguhnya manusia itu benar-benar dalam kerugian, 3. Kecuali orang-orang yang beriman \& mengerjakan amal saleh \& nasehat menasehati supaya mentaati kebenaran dan nasehat menasehati supaya menetapi kesabaran. (surah Al-Ashr:1-3)
4). Aqidah yang kokoh juga mengarahkan pada penghidupan yang lebih baik

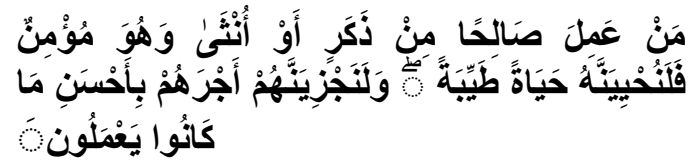

"Barangsiapa yang mengerjakan amal saleh, baik laki-laki maupun perempuan dalam keadaan beriman, Maka Sesungguhnya akan kami berikan kepadanya kehidupan yang baik[839] ${ }^{19}$ dan Sesungguhnya akan kami beri balasan kepada mereka dengan pahala yang lebih baik dari apa yang telah mereka kerjakan." (surah An-Nahl:97)

1) Aqidah yang kokoh melahirkan sikap konsekuen terhadap apa yang menjadi prinsipnya.

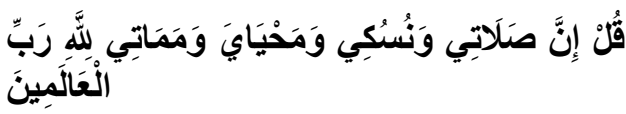

"Katakanlah: Sesungguhnya sholatku, ibadatku, hidupku dan matiku hanyalah untuk Allah, Tuhan semesta alam."(Surah Al-An'am:162)

2) Aqidah yang kokoh melahirkan keberuntungan dan kesuksesan.

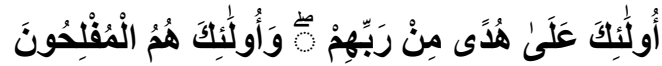

" Mereka Itulah yang tetap mendapat petunjuk dari Tuhan mereka, dan merekalah orang-orang yang beruntung ( orang-orang yang mendapat apa-apa yang dimohonkannya kepada Allah sesudah mengusahakannya)."(surah Albaqarah:5)

3) Aqidah yang kokoh menjadi penentram jiwa.

${ }^{19}$ Ditekankan dalam ayat Ini bahwa laki-laki dan perempuan dalam Islam mendapat pahala yang sama dan bahwa amal saleh harus disertai iman. 


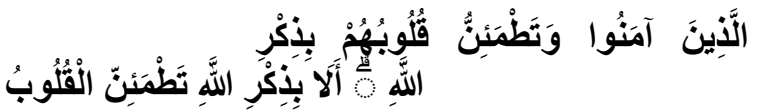

"(yaitu) orang-orang yang beriman dan hati mereka manjadi tenteram dengan mengingat Allah. Ingatlah, Hanya dengan mengingati Allah-lah hati menjadi tenteram." (surah Ar Ra'd:28)

4) Aqidah yang kokoh menjadi solusi kehidupan .

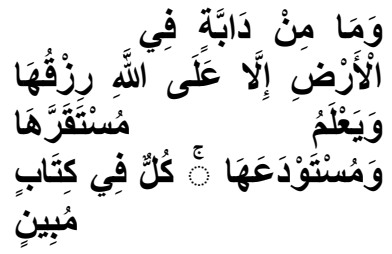

"Dan tidak ada suatu binatang melata ${ }^{20}$ pun di bumi melainkan Allah-lah yang memberi rezkinya, dan dia mengetahui tempat berdiam binatang itu dan tempat penyimpanannya ${ }^{21}$ semuanya tertulis dalam Kitab yang nyata (Lauh mahfuzh). (surah hud:6)

5) Aqidah yang kokoh menumbuhkan semangat ta'abbudiyah dan keyakinan pada Zat pemberi pertolongan "Hanya Engkaulah yang kami sembah ${ }^{22}$ dan Hanya kepada Engkaulah kami meminta pertolongan. ${ }^{23} 6$. Tunjukilah ${ }^{24}$ kami

\footnotetext{
${ }^{20}$ yang dimaksud binatang melata di sini ialah segenap makhluk Allah yang bernyawa.

${ }^{21}$ menurut sebagian ahli tafsir yang dimaksud dengan tempat berdiam di sini ialah dunia dan tempat penyimpanan ialah akhirat. dan menurut sebagian ahli tafsir yang lain maksud tempat berdiam ialah tulang sulbi dan tempat penyimpanan ialah rahim.

${ }^{22}$ Na'budu diambil dari kata 'ibaadat: kepatuhan dan ketundukkan yang ditimbulkan oleh perasaan terhadap kebesaran Allah, sebagai Tuhan yang disembah, Karena berkeyakinan bahwa Allah mempunyai kekuasaan yang mutlak terhadapnya. Qur'an in Word ver 1.0.0 (mushaf dan terjemahannya)

${ }^{23}$ Nasta'iin (minta pertolongan), terambil dari kata isti'aanah: mengharapkan bantuan untuk
}

jalan yang lurus, 7. (yaitu) jalan orang-orang yang Telah Engkau beri nikmat kepada mereka; bukan (jalan) mereka yang dimurkai dan bukan (pula jalan) mereka yang sesat." ${ }^{25}$ surah alfatihah :5-7

Aqidah yang kokoh menunjukkan arah tujuan hidup yang benar, mengukur kebahagiaan hidup tidak semata dengan ukuran keduniaan atau materi .

Aqidah yang kokoh menjadi benteng diri , mencegah diri dari prilaku kejahatan dan sia-sia.

Aqidah yang kokoh merupakan obat.

Sayyid sabiq telah menuliskan kutifannya berupa berita dari surat kabar "aldjamhuriyah" terbitan 29-11-62 dengan judul: para ulama berlari ke agama untuk mengobati orang-orang yang menderita penyakit syaraf: ": patut bergembiralahlah orang-orang yang berpegang teguh kepada agamanya dan yang tidak pernah goyah imannya oleh teori-teori Darwin dan Julian haksly serta lain-lain teoritikus yang meremehkan agama dan memandangnya tidak berguna dan tidak menjadi kebutuhan manusia dalam hiupnya di alam luas ini. Para ahli penyakit jiwa/syaraf hari ini tidak mendapati obat yang lebih mujarab dan senjata yang lebih ampuh untuk mengobati mereka selain dengan pengajaran agama dan iman kepada Allah, mengharapkan rahmatNya dan kekuasaanNya dikala segala usaha dan daya upaya gagal memenuhi harapan.

Percobaan dimulai dirumah sakit khusus para criminal yang sakit jiwa "ma heawar" di daerah New York. Percobaan dimulai dengan menggunakan agama sebagai sarana pengobatan disamping cara-

dapat menyelesaikan suatu pekerjaan yang tidak sanggup dikerjakan dengan tenaga sendiri.

${ }^{24}$ Ihdina (tunjukilah kami), dari kata hidayaat: memberi petunjuk ke suatu jalan yang benar. yang dimaksud dengan ayat Ini bukan sekedar memberi hidayah saja, tetapi juga memberi taufik.

${ }^{25}$ yang dimaksud dengan mereka yang dimurkai dan mereka yang sesat ialah semua golongan yang menyimpang dari ajaran Islam. 
cara biasa dan obat penenang.Dan ternyata dengan cara tersebut, mereka yang dirasa sudah tidak ada haapan sembuh,kembali menjadi orang yang normal dan sembuh penyakit jiwanya.Mereka yang sebelumnya melakukan tindakan-tindakan criminal tanpa sadar sebab didorong oleh penyakit jiwanya,kembali bertaubat dan dapat menguasai kehendaknya, fikirannya, prilakunya, dan bahkan memperlihatkan sesalan terhadap apa yang dilakukannya.

Maka menyerahlah para ulama, menganggat tangan ke langit seraya mengakui kelemahan manusiawi dan menyadari bahwa ilmu itu mengandung agama dan sangat bertentangan dengan kemurtadan/kekafiran. ${ }^{26}$

Dalam pendidikan islam begitu urgentnya penanaman nilai-nilai aqidah ini ditegakkan, karena ianya merupakan bekal utama anak didik mengarungi kehidupan nyata supaya hidupnya selamat dan bahagia dunia akherat.

Dan untuk merealisasikan pembentukan kepribadian yang islami diperlukan adanya berbagai metode pendidikan yang dianggap cukup representatif, di antaranya dengan menggunakan kalimah tauhid, keteladanan yang baik, nasihat, dan pembiasaan serta pengawasan.

Adapun kalimah tauhid adalah merupakan metode awal bagi orang tua untuk menanamkan aqidah kepada anaknya. Kalimah tauhid terangkai dalam adzan dan iqomat yang dikumandangkan di telinga sang anak sejak ia dilahirkan ke dunia.

Sedangkan metode keteladanan akan memberikan kontribusi yang sangat berarti bagi tercapainya tujuan pendidikan. Seorang pendidik harus mencerminkan sikap prilaku yang mulia.

Nasehat menjadi sarana penyampaian informasi yang benar mengenai aqidah yang murni.Penyampaian dengan metode ini tentunya dibarengi dengan perumpamaan dan kisah-kisah yang memberikan pengaruh terhadap jiwa anak didik.

26 Sayyid Sabiq,Sumber Kekuatan Islam,Penerbit PT Bina Ilmu,Surabaya,1980,hal 29-30.
Disamping itu pembiasaan yang baik juga tidak bisa ditinggalkan, karena membiasakan anak berfikir, bersikap dan berperilaku sesuai dengan ajaran agama Islam juga merupakan metode yang efektif dalam menanamkan nilai-nilai aqidah.

Dan pendidikan islam tentunya juga memperhatikan sisi pengawasan yang berkesinambungan, sehingga pembinaan yang dilaksanakan akan terkontrol dengan baik, sehingga nilai aqidah yang ditanamkan benar-benar terealisasi dalam keseharian anak didik.

\section{KESIMPULAN}

Penanaman aqidah dalam pendidikan islam menjadi penting dan mendesak sekali karena pengaruhnya yang sangat signifikan terhadap arah pergerakan atau prilaku seorang muslim dalam keseharian. Apalagi dalam pendidikan islam, anak-anak harus senantiasa diarahkan dan ditumbuhkembangkan potensinya sehingga ilmu yang telah dipelajari dan dipahami dapat selaras dengan amaliyahnya di kehidupan nyata.

Dan kita tidak boleh hanya merasa cukup dengan gambaran akal yang terbatas, akan tetapi kita harus menjadikan aqidah ini tertanam betul dalam akal-akal kita dan hati-hati kita, agar ianya dapat membuahkan ketaqwaan dan keistiqomahan atas perintah Allah SWT.

Dengan kata lain, bahwa landasan aqidah menjadi barometer pembentuk prilaku anak didik seutuhnya. Terutama di era dan zaman yang terus berkembang seperti sekarang ini dengan teknologi yang semakin canggih, dan tak luput dari berbagai tantangan yang semakin kompleks, maka disinilah dituntut penguatan penanaman aqidah dalam diri mereka, sehingga mereka tidak mudah terbawa arus akan tetapi menjadi kokoh dengan benteng aqidahnya yang murni dan lurus. Karena aqidah ibarat cahaya yang mampu menerangi semua sisi kehidupan manusia, tanpanya maka menjadi gelaplah semua sisi kehidupan. Aqidah ibarat ruh bagi jiwa manusia, tanpanya manusia tidak akan bernilai apa-apa. Wallahu'am. 


\section{DAFTAR PUSTAKA}

Abidin Ibn Rusn, Pemkiran al-Ghozali Tentang Pendidikan, Yogyakarta: Pustaka Pelajar, 1998.

Abu Daud Sulaiman bin Asy'as Sajastany, Sunan Abu Daud, Dar al Kitab al Araby, Beirut.

Ahmad bin hanbal, Musnad al Imam Ahmad bin Hanbal,Muassasah arRisalah, cet ke2, 1999.

Al Imam AnNawawy, Riyadhusholihin.Dar al afaq arabiyah,kairo.

Dr.M,Ajaj alKhathib, Usul al-Hadis, Gaya Media Pratama,Semarang 1997.

Malik bin Anas bin Malik, al Muwatho', Muassasah Zain bin Sulthan - Abu Dhabi-Imarat, 2004.

Muhammad bib Hibban bin Ahmad bin Muaz bin ma'bad atTamimy abu Hatim adDarimy, Shohih Ibnu Hibban, muassasah al risalah, Beirut 1993.

Sayyid Sabiq,Al Aqaid al Islamiyah ,Dar al Kitab al 'Araby, Beirut.

Sayyid Sabiq,Sumber Kekuatan Islam,Penerbit PT Bina Ilmu,Surabaya, 1980.

Yunahar Ilyas, Kuliah Aqidah Islam, Lembaga Pengkajian dan Pengamalan Islam (LPPI) Universitas Muhammadiyah Yogyakarta, 1993.

Qur'an in Word ver 1.0.0 (Mushaf alQur'an dan terjemahannya)created by Mohamad Taufik.. 